\title{
An Association Rule Analysis of Combined Acupoints for the Treatment of Patients with Dry Eye Disease
}

\author{
Ya-Hsuan Lin ${ }^{a}$ Hsein-Chang Wu ${ }^{a, b}$ Po-Chun Hsieh ${ }^{a} \quad$ I-Shiang Tzeng ${ }^{c}$ \\ Shu-Ya Wu ${ }^{d}$ Chan-Yen Kuo ${ }^{c}$ \\ a Department of Chinese Medicine, Taipei Tzu Chi Hospital, Buddhist Tzu Chi Medical Foundation,

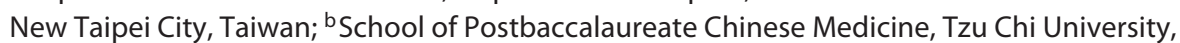 \\ New Taipei City, Taiwan; ' Department of Research, Taipei Tzu Chi Hospital, Buddhist Tzu Chi Medical Foundation, \\ New Taipei City, Taiwan; ${ }^{d}$ Department of Ophthalmology, Taipei Tzu Chi Hospital, Buddhist Tzu Chi Medical \\ Foundation, New Taipei City, Taiwan
}

\section{Keywords}

Combination acupuncture · Association rule analysis · Dry eye disease $\cdot$ Data mining

\begin{abstract}
Background: Dry eye disease (DED) has a higher incidence in old age and is seen predominantly in females worldwide. Neurosensory abnormalities, ocular surface inflammation and damage, film instability, and hyperosmolarity are major and proven pathologies responsible for a poor quality of life. Tear breakup time and Schirmer's I test are predominantly used for the evaluation of primary outcomes in patients undergoing conventional treatment. A previous meta-analysis of some relevant studies proved that combination of acupoints could be more effective than single acupoint treatment. Objectives: The present study aimed to undertake association rule mining and examined the potential kernel acupoint combination in DED treatment constructed from the extracted randomized controlled trials (RCTs) based on a previous meta-analysis. Methods: We summarized 32 acupoints as binary data from the 12 eligible RCTs and analyzed them based on the Apriori algorithm. Results: TE23, BL2, ST2, ST1, EX-HN5, BL1, LI4, ST36, SP6, and KI3 were the 10 most frequently selected acupoints. The major associated rules in combination of acupoints were $\{$ TE23, LI $\}\}\{\{$ ST 1$\}$ and $\{$ TE23, $\mathrm{ST} 1\} \geq\{\mathrm{LI}\}\}$, as inferred from 23 association rules. Conclu-
\end{abstract}

sions: For acupuncture treatment of DED, combined TE23, LI4, and ST1 acupoints could be settled as the kernel of acupoint combination.

(c) 2020 The Author(s) Published by S. Karger AG, Basel

\section{Assoziationsanalyse von Akupunkt-Kombinationen zur Behandlung von Patienten mit Syndrom des trockenen Auges}

\section{Schlüsselwörter}

Kombinations-Akupunktur - Assoziationsanalyse • Syndrom des trockenen Auges · Data Mining

\section{Zusammenfassung}

Hintergrund: Das Syndrom des trockenen Auges tritt im höheren Alter mit steigender Inzidenz auf; weltweit sind vorwiegend Frauen betroffen. Neurosensorische Anomalien, Entzündung und Schädigung der Augenoberfläche, Instabilität des Tränenfilms und Hyperosmolarität sind schwerwiegende nachgewiesene Pathologien, die die Lebensqualität erheblich beeinträchtigen. Die TränenfilmAufrisszeit und der Schirmer-I-Test sind die gängigsten Mittel zur Beurteilung primärer Outcomes bei Patienten unter konventioneller Behandlung. Eine frühere Metaanalyse mehrerer relevanter Studien ergab, dass eine

\section{karger@karger.com}

www.karger.com/cmr

Karger $\frac{1}{\%}$

BOPEN ACCESS
(C) 2020 The Author(s)

Published by S. Karger AG, Base

This is an Open Access article licensed under the Creative Common Attribution-NonCommercial-4.0 International License (CC BY-NC) (http://www.karger.com/Services/OpenAccessLicense), applicable to the online version of the article only. Usage and distribution for commercial purposes requires written permission. 
Kombination von Akupunkten wirksamer sein könnte als die Behandlung eines einzelnen Akupunkts. Ziele: Das Ziel dieser Studie war ein assoziationsanalytisches Data Mining einer potenziellen Kern-Akupunkt-Kombination für die Behandlung des trockenen Auges, welche auf der Grundlage einer früheren Metaanalyse von extrahierten randomisierten, kontrollierten Studien (RKS) konstruiert wurde. Methode: Wir fassten 32 Akupunkte als binäre Daten aus 12 RKS, die unsere Anforderungen erfüllten, zusammen und analysierten sie auf der Grundlage des Apriori-Algorithmus. Ergebnisse: TE23, BL2, ST2, ST1, EX-HN5, BL1, LI4, ST36, SP6 und KI3 waren die 10 am häufigsten ausgewählten Akupunkte. Die wichtigsten assoziierten Regeln für Akupunkt-Kombinationen lauteten $\{$ TE23, LI4\} $\geq\{\mathrm{ST} 1\}$ und $\{$ TE23, ST 1$\} \geq\{$ LI4 $\}$, wie aus 23 Assoziationsregeln abgeleitet wurde. Schlussfolgerungen: Für die Akupunkturbehandlung des trockenen Auges konnten die Akupunkte TE23, LI4 und ST1 als Kern der Akupunkt-Kombinationen ermittelt werden.

๑) 2020 S. Karger AG, Base

\section{Introduction}

The incidence of dry eye disease (DED), characterized by dryness or a gritty sensation, an ocular surface disorder and even blurred vision or ocular pain $[1,2]$, is increasing, with a predominance of old age and female sex [2, 3]. In the past 2 decades, based on collective experience and knowledge, some relevant organizations had updated the definition of DED. In 1995, the National Eye Institute/ Industry working group officially defined the clinical trials in dry eye [4], followed in 2007 by the Tear Film and Ocular Surface Society Dry Eye Workshop I [5]. In recent years, hyperosmolarity, ocular surface inflammation and damage, and neurosensory abnormalities are included in the main pathology, as suggested by the Tear Film and Ocular Surface Society International Dry Eye Workshop II, and the definition of DED has also been revised in 2017. Although DED may not be completely curable, signs and symptoms may alleviate after treatment [6]. However, the severity of patient symptoms is not always related to the severity of signs on ophthalmological evaluation [7]. Reducing clinical symptoms along with a decrease in objective signs are the treatment goals to improve patients' quality of life. Therapy includes reducing environmental causes and, if possible, discontinuing medications that may cause or worsen dry eye [8]. Patient signs and symptoms may be re-evaluated, once these have been addressed. When clinical signs and symptoms persist, the use of tear substitutes is recommended for most patients. If these are insufficient, ophthalmologists prescribe other treatments based on the severity of the dry eye and patient preferences.
The main signs and symptoms of DED may include ocular irritation and discomfort, photosensitivity, eye fatigue, redness, itching, mucous discharge, visual blurring, and decreased tear meniscus or breakup time (BUT) [9]. Patients often complain that ocular irritation and blurred vision worsen through the day. As the day progresses, the use of computers, other electronic devices, or reading often bothers them more. Patients may mention that they feel like they have something in their eye, a foreign body sensation [10]. The ophthalmologist will obtain a medical and ocular history and perform a comprehensive eye evaluation when a patient presents with symptoms indicative of DED. External eye examination and slit lamp biomicroscopy are performed to document dry eye signs, evaluate the tear film, and determine whether the patient has other causes of ocular irritation [6]. Ophthalmic tests include tear BUT, tear osmolarity, aqueous tear production, ocular surface dye staining, and lachrymal gland function tests [6]. If a systemic disease such as Sjögren's syndrome is suspected, additional laboratory tests will be performed, for example, blood tests for anti-Sjögren's syndrome A or B antibody and rheumatoid factor. Ophthalmologists may classify patients as having mild, moderate, or severe DED, but the signs and symptoms often overlap [11]. As the level of a patient's subjective symptoms may not be related to the objective findings on ocular examination and testing, the treatment must be tailored for each individual patient [11].

Treatment will relieve patients' signs and symptoms but will not cure DED. Environmental modifications, eyelid abnormality correction and eyelid compresses, treatment of ocular problems such as blepharitis, wherever possible, the discontinuation of ophthalmic or systemic medications that may cause dry eye, $\omega-3$ fatty acids from diet or supplements, artificial tear solutions, artificial tear gels or ointments, cyclosporine ophthalmic drops, spectacle side-shields, special contact lenses, punctal plugs, autologous serum tears, and permanent punctal occlusion are the commonly used treatment options for mild, moderate, and severe DED (online suppl. Table 1; see www.karger.com/doi/10.1159/000512674 for all online suppl. material). All of these attempt to decrease subjective symptoms and objective signs [12].

Acupuncture received more attention due to its complementary and alternative effects in alleviating the symptoms of certain diseases safely. Meanwhile, acupuncture is a useful Chinese medicine treatment which suggested that it could be an effective method for the treatment of DED patients in the near future. In fact, to improve the symptoms of patients with DED, a previous meta-analysis [13] stated that acupuncture along with Chinese herbs is a tolerable and effective nonpharmacological treatment. The relationship between acupuncture points and diseases to improve the therapeutic effect of the treatment 
Table 1. Summary of the retrieved studies

\begin{tabular}{llllllll}
\hline $\begin{array}{l}\text { First } \\
\text { author }\end{array}$ & Year & Country & $\begin{array}{l}\text { Sample } \\
\text { size }\end{array}$ & Diagnosis & Acupoints & $\begin{array}{c}\text { Overall } \\
\text { bias }\end{array}$ & $\begin{array}{l}\text { BUT and } \\
\text { SIT outcomes } \\
\text { measured }\end{array}$ \\
\hline Nepp [31] & 1998 & Austria & 52 & DED & GB1, BL2, EX_HN2, ST5, LI4, SI3, LI3, KI6, TE5 & Low & Yes \\
\hline Wang [32] & 2005 & China & 45 & DED & $\begin{array}{l}\text { LI11, LI4, SP6, KI3, ST2, LI20, SP10, SP9, ST36, ST40, BL2, } \\
\text { TE23, GB14, ST1 }\end{array}$ & Low & Yes \\
\hline Tseng [33] & 2006 & Taiwan & 43 & DED & EX-HN5, TE23, GB14, ST2, SP6 & Low & Yes \\
\hline Shi [34] & 2012 & China & 68 & DED & ST1, BL1, EX-HN5, TE23, GV20, LI4, ST36 & Low & Yes \\
\hline Kim [35] & 2012 & South Korea & 150 & DED & ST1, BL2, TE23, GB14, EX1, GV23, GB20, LI4, LI11 & Low & Yes \\
\hline Liao [36] & 2013 & China & 40 & DED & BL1, ST1, TE23, EX-HN4, KI3, LR3, SP6, ST36 & Low & Yes \\
\hline Nan [37] & 2014 & China & 60 & DED & $\begin{array}{l}\text { Eye acupuncture related to liver area, gallbladder area, } \\
\text { kidney area, spleen stomach area, and upper jiao area }\end{array}$ & Low & Yes \\
\hline Zeng [38] & 2014 & China & 52 & DED & GB1, BL1, LI20, BL2, ST2, EX-HN5, SP6, SP10, ST36, KI3 & Low & Yes \\
\hline Shang [39] & 2015 & China & 148 & DED & BL1, EX-HN5, ST2 & Low & Yes \\
\hline Xiang [40] & 2016 & China & 88 & DED & BL2, TE23, ST2 & Low & Yes \\
\hline Liu [41] & 2017 & China & 28 & DED & BL1, BL2, TE23, EX-HN5, ST2, ST1, LI4, GB20, GV20 & Low & Yes \\
\hline Huang [42] & 2013 & China & 126 & DED & ST1, BL1, BL2, EX-HN7, LU7, GB37, KI3, LR3, EX-HN5 & Low & Yes \\
\hline
\end{tabular}

DED, dry eye disease; SIT, Schirmer's I test; BUT, tear breakup time.

has been widely used in the fields of modern as well as Chinese medicine. Based on data mining results, a previous study provided a reference for the selection and combination of acupuncture points for treating various eye diseases with clinical acupuncture therapy [14]. Another research [15] also provided some valuable suggestions in the selection and combination of acupuncture points for DED. Data mining has been widely used to uncover potential acupuncture points to effectively treat specific diseases, based on literature review. Through a data mining approach, a study examined the principles of acupuncture point selection and characteristics for primary dysmenorrhea. As a matter of fact, association rules mining (analysis) is generally used in marketing to decide strong and frequent directional associations between jointly purchased items [16].

In this study, we intended to mine the potential kernel combination of acupuncture points for the treatment of DED based on acupoint data from a previous meta-analysis [13].

\section{Materials and Methods}

\section{Data Sources}

Acupoint data were extracted from a meta-analysis [13], which integrated acupuncture data defined by the content of the WHO Standard Acupuncture Point Integration of 32 acupuncture point locations among 12 extracted studies from the aforementioned study. We recorded 32 acupuncture point locations included in the studies as binary data (online suppl. Table 2).

\section{Risk of Bias Assessment}

The Cochrane RoB 2.0 tool was used to assess quality of the studies. The tool for the risk of bias including selection bias, performance bias, detection bias, attrition bias, and reporting bias which combined to an overall bias to assess the quality of randomized controlled trials (RCTs). Note that the previous meta-analysis described the detail of the quality assessment of 12 retrieved RCTs.

Data Analysis

Association rule analysis and plotting were based on package "arules" and "arulesViz" installed with statistical software R (version 4.0.0). Support, confidence, expected confidence, and lift were 4 kernel values involved with association rule analysis. Theoretically, support means the fraction of the total number of transactions in which the item set occurs. And confidence presented the conditional probability of occurrence of consequent, given the antecedent. Next, expected confidence defines the probability of the consequent while consequent was independent of the antecedent. The lift value equals the ratio of joint antecedent and a consequent probability and product of each marginal probability.

\section{Results}

\section{Study Characteristics and Risk of Bias Assessment}

The summary of the 12 retrieved studies and quality assessment with overall bias are presented in Table 1 . The results of the risk of bias assessment founded no serious risk of bias (refer to online suppl. Fig. 1 and 2). 
Fig. 1. Acupoint distribution extracted from 12 RCTs.

Fig. 2. Twenty-three association rules presented as a scatter plot.
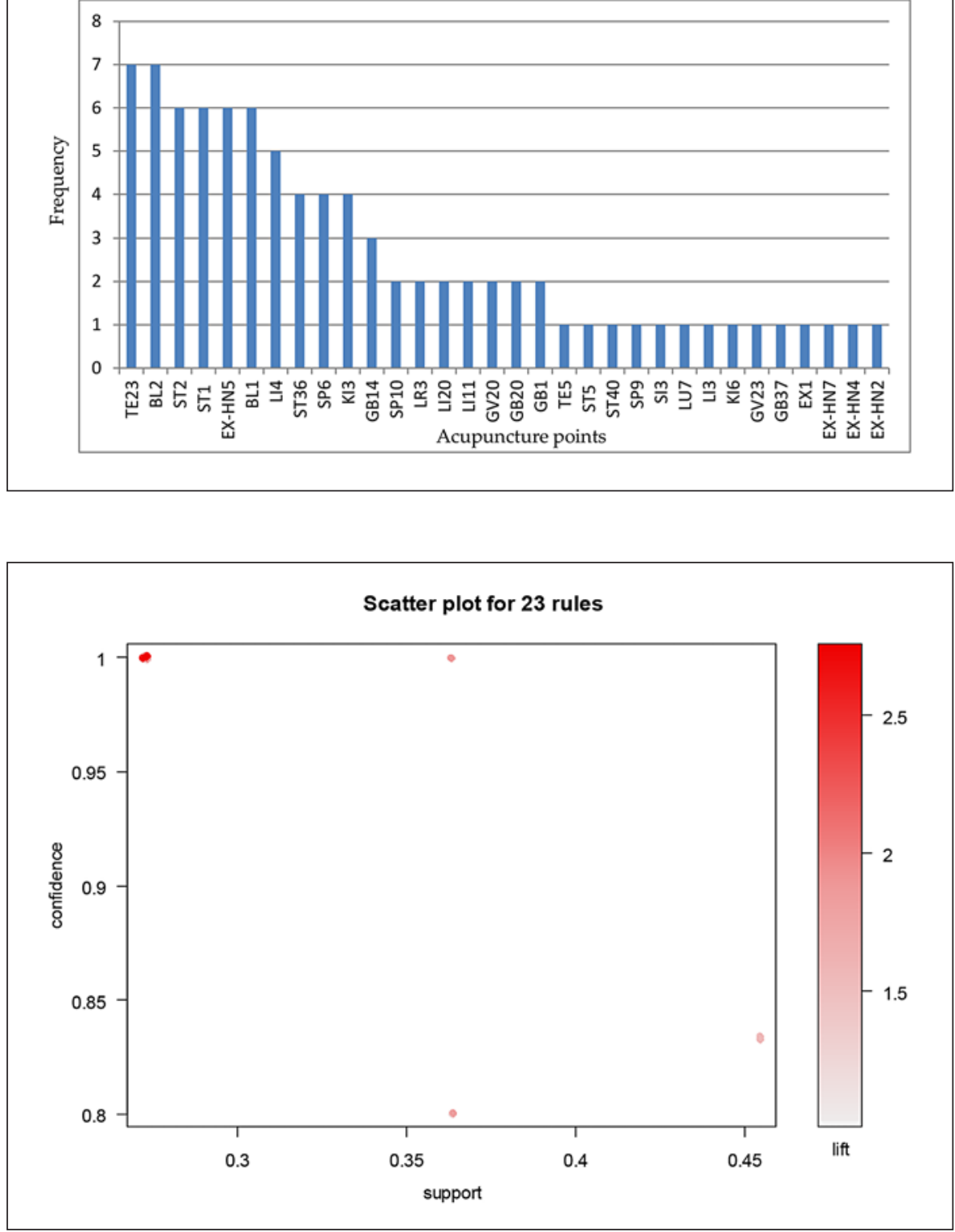

\section{Acupoint Distribution}

From the aforementioned meta-analysis, various acupoints were extracted from the 12 retrieved RCTs. The summary of various acupoints from the 12 retrieved studies is shown in Table 1. After categorization of various acupoints from the 12 retrieved studies, we found 32 different acupoints used in the previous meta-analysis [13]. Figure 1 presents the frequency distribution of the 32 different acupoints. TE23, BL2, ST2, ST1, EX-HN5, BL1, LI4, ST36, SP6, and KI3 were the 10 most frequently selected acupoints for the treatment of DED and related symptoms.
Acupoint Combinations Based on Association Rule Analysis for Item Sets

Online supplementary Table 2 summarizes 32 acupoint data. Figure 2 presents a scatter plot to show that all rules had great improvement. The support/confidence border can be detected for the optimal rules (i.e., the most interesting rules) according to a previous study [17]. The top 10 interesting association rules are listed and ordered by support in Table 2 . Figure 3 visually presents the features colored according to a grouped matrix of 10 association rules. Figure 4 interactively demonstrates that $\{$ TE23, LI4 $\} \geq\{$ ST1 $\}$ and $\{$ TE23, ST1 $\} \geq\{$ LI4 $\}$ reveal the rule's located near the eyes and hands. In Table 2 results of the grouped matrix of 10 associations were matched for rule numbers $7(\{\mathrm{LI} 4, \mathrm{TE} 23\} \geq\{\mathrm{ST} 1\})$ and $8(\{\mathrm{LI} 4, \mathrm{ST} 1\} \geq$ $\{$ TE23 $\}$ ). 


\section{Grouped Matrix for 10 Rules}

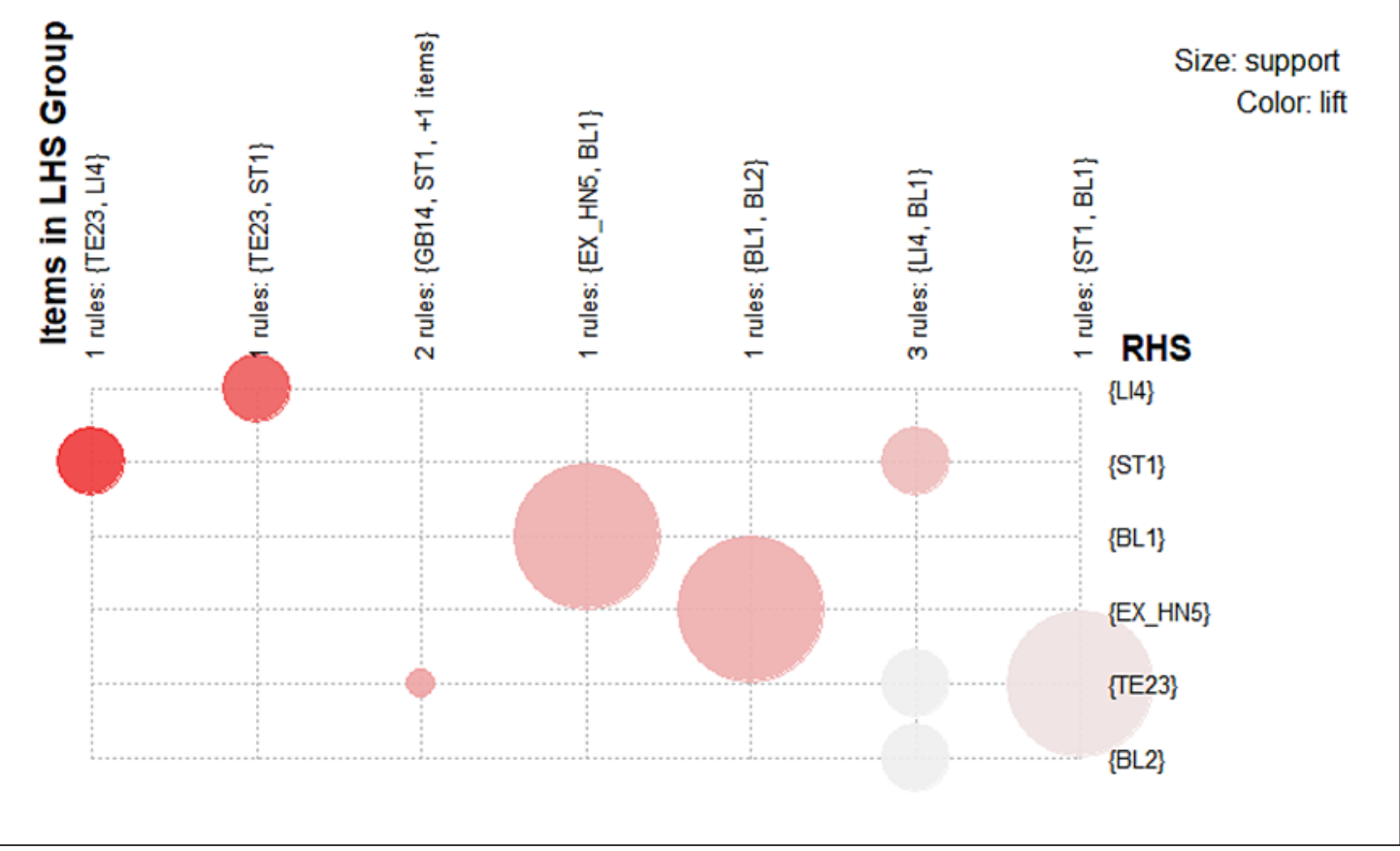

Fig. 3. Ten association rules presented as grouped matrix. LHS, left-hand side; RHS, right-hand side.

Table 2. Top 10 optimal acupuncture association rules

\begin{tabular}{|c|c|c|c|c|c|}
\hline No. & Association rules & Support & Confidence & $\begin{array}{l}\text { Expected } \\
\text { confidence }\end{array}$ & Lift \\
\hline 1 & EX-HN5 $\geq$ BL1 & 0.4545455 & 0.8333333 & 0.5454544 & 1.527778 \\
\hline 2 & BL1 $\geq$ EX-HN5 & 0.4545455 & 0.8333333 & 0.5454544 & 1.527778 \\
\hline 3 & $\mathrm{ST} 1 \geq \mathrm{TE} 23$ & 0.4545455 & 0.8333333 & 0.6363635 & 1.309524 \\
\hline 4 & $\mathrm{LI} 4 \geq \mathrm{TE} 23$ & 0.3636364 & 0.8000000 & 0.6363636 & 1.257143 \\
\hline 5 & $\mathrm{LI} 4 \geq \mathrm{ST} 1$ & 0.3636364 & 0.8000000 & 0.5454544 & 1.466667 \\
\hline 6 & $\mathrm{LI} 4 \geq \mathrm{BL} 2$ & 0.3636364 & 0.8000000 & 0.6363636 & 1.257143 \\
\hline 7 & LI4, TE23 $\geq$ ST1 & 0.3636364 & 1.0000000 & 0.5454546 & 1.833333 \\
\hline 8 & LI4, ST $1 \geq$ TE23 & 0.3636364 & 1.0000000 & 0.6363634 & 1.571429 \\
\hline 9 & ST1, TE23 $\geq$ LI4 & 0.3636364 & 0.8000000 & 0.4545454 & 1.760000 \\
\hline 10 & GB14 $\geq$ TE23 & 0.2727273 & 1.0000000 & 0.6363634 & 1.571429 \\
\hline
\end{tabular}

\section{Discussion}

Dry eye occurs when there is a dysfunction in tear production, or tear consistency, or when tears evaporate too quickly. This often leads to inflammation of the eye surface, which may cause pain, scarring of the cornea, vision loss, and ulcerations. There are 2 main causes of DED. The first is insufficient water content in the tears produced by the lachrymal glands. Another cause is inflammation of the meibomian glands. These are large sebaceous glands of the eyelids that form the oily part of tears to slow evaporation and promote tear stability. Inflammation of these glands inhibits their normal functioning.

Our results suggest that combining TE23, LI4, and ST1 acupoints could be considered as the kernel of acupoints in treating patients with DED. In a previous meta-analysis [13], this acupoint combination played a vital role in strengthening primary outcomes in patients with DED under conventional treatment, including artificial tears or other nonacupuncture therapies. To the best of our knowledge, the initial research relied on evidence-based strategies to highlight the potential kernel acupoint com- 


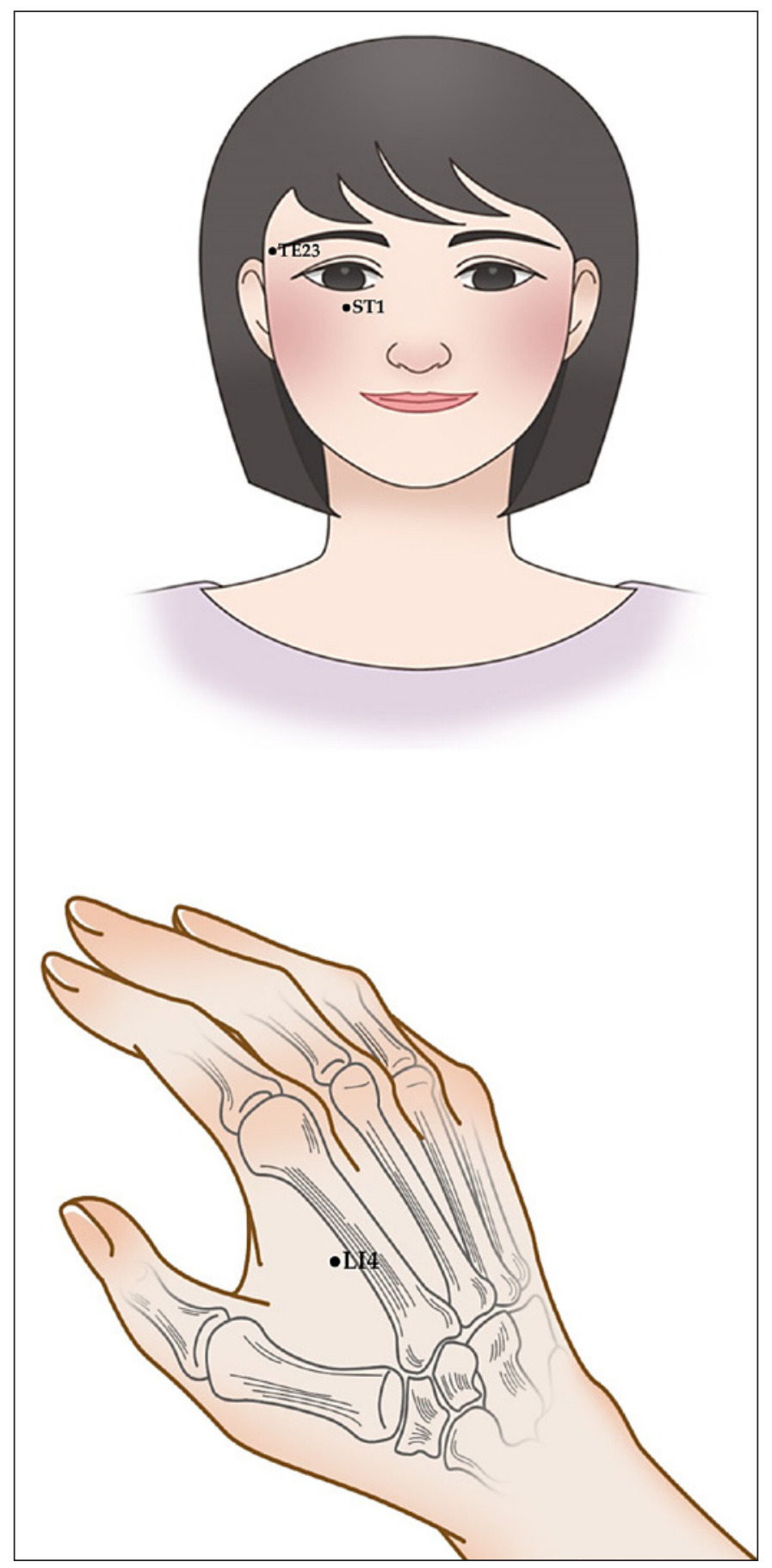

Fig. 4. Location of the kernel acupoints in treating patients with DED.

bination in treating patients with DED. Kernel acupoint combinations are advantageous for patients with DED, as confirmed by the present study. Previous studies have shown that major acupuncture points for treatment of DED are located near the eyes and hands. It is important to investigate the possible mechanism for the effect of kernel acupoint combinations. TE23, LI4, and ST1 acupoints were also located near the eyes and hands. Accord- ing to previous reports, a possible core mechanism of DED is inflammation [18]. Acupuncture benefits reported include decreased proinflammatory cytokines [19], anti-inflammatory effects [20], and improvements in scratchiness [21] and redness [22]. To our knowledge, inflammatory conditions, hormonal imbalances, and related disorders are correlated with biomedical mechanisms.

Gender differences existing at the hormonal level affect ocular structure, functioning, and health. This includes both basal and life span-associated levels of sex steroids (mainly androgens and estrogens), as well as female-specific hormones that affect menstruation, pregnancy, and menopause. The levels of many sex steroids, such as testosterone, 4-androstene-3, 17-dione, estrone, $17 \beta$-estradiol, progesterone, 17 $\alpha$-hydroxyprogesterone, and especially estrogen may be associated with DED [2327].

In clinical practice, acupuncture treatment seems to be more effective than artificial tears for DED [28]. After treatment, the acupuncture group had a significant entire BUT, which was longer than the artificial tear group. In addition, the acupuncture group had a significantly higher Schirmer's I test than the artificial tear group after treatment.

It has been demonstrated that acupuncture on BL1, BL2, MHN9, ST2, LI4, SP6, GB20, and KD3 increased lachrymal gland secretion, improved tear film stability, and slowed tear film breakdown in patients receiving a combined acupuncture plus lubricant eye drop treatment, compared to patients receiving only lubricant eye drop treatment $[29,30]$. In a previous review, BL1, BL2, ST1, ST2, TE23, and EX-HN5 were the frequently used acupoints in clinical trials involving dry eye management [29].

Our study had a few constraints, although we purposed the kernel of acupoint combination. In our analysis, we mentioned this meta-analysis, including nonSjögren's syndrome participants, and excluded combined treatments that might improve the outcome of acupuncture. Acupuncture therapy is effective in improving BUT and Schirmer's I test in dry eye patients, and slightly better than artificial tear treatment, as proven by the current evidence. Although this review included a total of 900 participants from 12 studies, it still had small sizes. We undoubtedly need RCTs having a double-blind design with objective outcomes, high quality and large sample size to be implemented for long treatment duration, to assess the efficacy and acceptability of acupuncture in the population and to obtain a definitive conclusion in the future. The mechanism of treatment of dry eye by acupuncture is still unclear, with combination acupuncture being one of the oldest interventions. A comprehensive evaluation based on further studies needs to be conducted in the future. 


\section{Conclusions}

Combined TE23, LI4, and ST1 could be viewed as the kernel acupoint combination for further acupuncture therapies of DED. Hitherto, acupuncture was regarded as a possible, but not dependable therapy, because it lacked reproducible verification. According to our analysis, this kernel acupoint combination is suggested for further verification through clinical trials, basic mechanism research, and treatment strategies.

\section{Acknowledgments}

This work was also supported by a grant from the Ministry of Science and Technology, Taiwan (109-2320-B-303-004-MY3).

\section{Statement of Ethics}

The paper is exempt from Ethical Committee approval.

\section{Conflict of Interest Statement}

The original data used to support the findings of this study are included in the article. Additionally, the authors declare no conflicts of interest.

\section{Author Contributions}

Y.-H.L. and C.-Y.K. created the research idea, performed the analysis, wrote the results and discussion, and contributed to the literature review. H.-C.W., P.-C.H., and S.-Y.W. provided clinical suggestions and helped revise the manuscript. I.-S.T. supported the literature review and analysis. C.-Y.K. prepared the paper for submission. All authors read and approved the final paper.

\section{References}

1 Miljanović B, Dana R, Sullivan DA, Schaumberg DA. Impact of dry eye syndrome on vision-related quality of life. Am J Ophthalmol. 2007 Mar; 143(3):409-15.

2 Barabino S, Labetoulle M, Rolando M, Messmer EM. Understanding Symptoms and Quality of Life in Patients With Dry Eye Syndrome. Ocul Surf. 2016 Jul;14(3):365-76.

3 Farrand KF, Fridman M, Stillman IO, Schaumberg DA. Prevalence of Diagnosed Dry Eye Disease in the United States Among Adults Aged 18 Years and Older. Am J Ophthalmol. 2017 Oct; 182:90-8.

4 Lemp MA. Report of the National Eye Institute/Industry workshop on Clinical Trials in Dry Eyes. CLAO J. 1995 Oct;21(4):221-32.

5 The definition and classification of dry eye disease: report of the Definition and Classification Subcommittee of the International Dry Eye WorkShop (2007). Ocul Surf. 2007 Apr; 5(2):75-92.

6 Akpek EK, Amescua G, Farid M, Garcia-Ferrer FJ, Lin A, Rhee MK, et al.; American Academy of Ophthalmology Preferred Practice Pattern Cornea and External Disease Panel. Dry Eye Syndrome Preferred Practice Pattern ${ }^{\circledR}$. Ophthalmology. 2019 Jan;126(1):286P334.

7 Bron AJ, Tomlinson A, Foulks GN, Pepose JS, Baudouin C, Geerling G, et al. Rethinking dry eye disease: a perspective on clinical implications. Ocul Surf. 2014 Apr; 12 (2 Suppl):S1-31.

8 Foulks GN, Forstot SL, Donshik PC, Forstot JZ, Goldstein MH, Lemp MA, et al. Clinical guidelines for management of dry eye associated with Sjögren disease. Ocul Surf. 2015 Apr;13(2):118-32.

9 Milner MS, Beckman KA, Luchs JI, Allen QB, Awdeh RM, Berdahl J, et al. Dysfunctional tear syndrome: dry eye disease and associated tear film disorders - new strategies for diagnosis and treatment. Curr Opin Ophthalmol. 2017 Jan;27 Suppl 1:3-47.
10 Benitez-Del-Castillo JM. How to promote and preserve eyelid health. Clin Ophthalmol. 2012;6:1689-98.

11 Dogru M, Nakamura M, Shimazaki J, Tsubota K. Changing trends in the treatment of dryeye disease. Expert Opin Investig Drugs. 2013 Dec;22(12):1581-601.

12 Alves M, Fonseca EC, Alves MF, Malki LT, Arruda GV, Reinach PS, et al. Dry eye disease treatment: a systematic review of published trials and a critical appraisal of therapeutic strategies. Ocul Surf. 2013 Jul;11(3):181-92.

13 Wei QB, Ding N, Wang JJ, Wang W, Gao WP. Acupoint selection for the treatment of dry eye: A systematic review and meta-analysis of randomized controlled trials. Exp Ther Med. 2020 Apr;19(4):2851-60.

14 Li TY, Xing HJ, Xu YY, Shi J, Wang JL, Sun $\mathrm{YH}$, et al. [Features of clinical application of eye acupuncture therapy revealed by data mining]. Zhen Ci Yan Jiu. 2019 May;44(5): 377-82.

15 Ma XJ, Zhao YD, Zhang GX, Zhao CZ. [The rules of acupoint selection of acupuncture for dry eye]. Zhongguo Zhenjiu. 2019 Jan;39(1): 87-90.

16 Yu S, Yang J, Yang M, Gao Y, Chen J, Ren Y, et al. Application of acupoints and meridians for the treatment of primary dysmenorrhea: a data mining-based literature study. Evid Based Complement Alternat Med. 2015;2015: 752194.

17 Skarga-Bandurova I, Biloborodova T, Nesterov $M$. Extracting Interesting Rules from Gestation Course Data for Early Diagnosis of Neonatal Hypoxia. J Med Syst. 2018 Dec; 43(1):8.

18 Wei Y, Asbell PA. The core mechanism of dry eye disease is inflammation. Eye Contact Lens. 2014 Jul;40(4):248-56.

19 Jeong HJ, Hong SH, Nam YC, Yang HS, Lyu YS, Baek SH, et al. The effect of acupuncture on proinflammatory cytokine production in patients with chronic headache: a preliminary report. Am J Chin Med. 2003;31(6):945-54.
20 Zhang L, Yuan H, Zhang L, Li J, Li H. Effect of acupuncture therapies combined with usual medical care on knee osteoarthritis. J Tradit Chin Med. 2019 Feb;39(1):103-10.

21 Dhaliwal DK, Zhou S, Samudre SS, Lo NJ, Rhee MK. Acupuncture and dry eye: current perspectives. A double-blinded randomized controlled trial and review of the literature. Clin Ophthalmol. 2019 Apr;13:731-40.

22 Gao Y, Lin W, Zhou S, Shi G, He J, Chen Y. Treatment of Rosacea using acupuncture for improving the local skin microcirculation: A case report. Medicine (Baltimore). 2018 Aug; 97(34):e11931.

23 Duarte MC, Pinto NT, Moreira H, Moreira AT, Wasilewski D. [Total testosterone level in postmenopausal women with dry eye]. Arq Bras Oftalmol. 2007 May-Jun;70(3):465-9.

24 Gagliano C, Caruso S, Napolitano G, Malaguarnera G, Cicinelli MV, Amato R, et al. Low levels of $17-\beta$-oestradiol, oestrone and testosterone correlate with severe evaporative dysfunctional tear syndrome in postmenopausal women: a case-control study. Br J Ophthalmol. 2014 Mar;98(3):371-6.

25 Sriprasert I, Warren DW, Mircheff AK, Stanczyk FZ. Dry eye in postmenopausal women: a hormonal disorder. Menopause. 2016 Mar;23(3):343-51.

26 Pieragostino D, Agnifili L, Cicalini I, Calienno R, Zucchelli M, Mastropasqua L, et al. Tear Film Steroid Profiling in Dry Eye Disease by Liquid Chromatography Tandem Mass Spectrometry. Int J Mol Sci. 2017 Jun; 18(7):E1349.

27 Sullivan DA, Rocha EM, Aragona P, Clayton JA, Ding J, Golebiowski B, et al. TFOS DEWS II Sex, Gender, and Hormones Report. Ocul Surf. 2017 Jul;15(3):284-333.

28 Yang L, Yang Z, Yu H, Song H. Acupuncture therapy is more effective than artificial tears for dry eye syndrome: evidence based on a meta-analysis. Evid Based Complement Alternat Med. 2015;2015:143858. 
29 Kim BH, Kim MH, Kang SH, Nam HJ. Optimizing acupuncture treatment for dry eye syndrome: a systematic review. BMC Complement Altern Med. 2018 May;18(1):145.

30 Zhu D, Gao C, Zhong YM. [Clinical observation of dry eye syndrome treated with acupuncture]. Zhongguo Zhenjiu. 2019 Aug; 39(8):837-40.

31 Nepp J, Wedrich A, Akramian J, Derbolav A, Mudrich C, Ries E, Schauersberger J. Dry eye treatment with acupuncture. A prospective, randomized, double-masked study. Adv Exp Med Biol. 1998;438:1011-6.

32 Wang ZL, He HQ, Huang D, Shi CG. Effect of integral syndrome differentiation acupuncture on the tear film stability in the patient of xerophthalmia. Chin Acupunct Moxibustion. 2005;25:460-3.

33 Tseng K, Liu H, Tso K, Woung L, Su Y, Lin J. A clinical study of acupuncture and SSP (silver spike point) electro-therapy for dry eye syndrome. Am J Chin Med. 2006;34:197-206.
34 Shi J, Miao W. Effects of acupuncture on lactoferrin content in tears and tear secretion in patients suffering from dry eyes: a randomized controlled trial. J Chin Integr Med. 2012; 10:1003-8.

35 Kim TH, Kang JW, Kim KH, Kang KW, Shin MS, Jung SY, et al. Acupuncture for the treatment of dry eye: a multicenter randomised controlled trial with active comparison intervention (artificial teardrops). PLoS One. 2012;7:e36638

36 Liao L, Wei Q, Gong X. Effects of nourishing liver and kidney by acupuncture for vision related quality of life in perimenopausal women with dry eye. J Trad Chin Ophthalmol. 2013; 23:403-6.

37 Nan H. Clinical observation of 60 cases of dry eye syndrome by the treatment of eye acupuncture combining the artificial tears. Wuhan: Hubei University of Chinese Medicine; 2014.
38 Zeng Z, Ma Q, Song C, Xia H. Clinical observation on 28 cases of dry eye after LASIK treated by acupuncture and artificial tear. Hunan J Trad Chin Med. 2014;30:105-7.

39 Shang XJ. Therapeutic observation of acupuncture at phenomaxillary ganglia for dry eye syndrome. Shanghai J Acu Mox. 2015;9: 870-2.

40 Xiang S, Jiang X, Li Y, Dou R. The efficacy of acupuncture at phenomaxillary ganglion and periocular acupoint for the treatment of dry eye. J Zhejiang Univ Trad Chin Med. 2016;40: 730-4.

41 Liu Q, Liu J, Ren C, Cai W, Wei Q, Song Y, Yu J. Proteomic analysis of tears following acupuncture treatment for menopausal dry eye disease by two-dimensional nano-liquid chromatography coupled with tandem mass spectrometry. Int J Nanomed. 2017;12:166371.

42 Huang R, Wu X, Li D. Observation on therapeutic effect of acupuncture on dry eye. Chin J Information TCM. 2013;20:67-8. 